\title{
A manera de presentación
}

Este cuarto número de la Revista de museología Kóot ofrece siete artículos, que con gusto la Dirección de Cultura de la Universidad Tecnológica de El Salvador presenta a la comunidad académica. Esta edición tiene como tema "Museos y patrimonio subacuático". Empezamos a darnos cuenta, en el país, de que los museos son verdaderos espacios culturales para el resguardo, conservación y exhibición del patrimonio del que es rica la nación; y cada vez nos encontramos con más iniciativas por parte de personas, a título personal; pero también por comunidades organizadas en querer crear museos. Esto significa que, poco a poco, hay una especie de toma de conciencia sobre la importancia de estos espacios para educar en temas específicos concernientes al patrimonio; pero también educar para la vida y para la sana convivencia, aprendiendo a ver y respetar los referentes del pasado que los museos muestran al público que los visita, además de ese patrimonio tangible e intangible que abunda en nuestro país.

En lo que respecta al patrimonio subacuático sabemos — por los recientes estudios de arqueólogos nacionales-, que en las costas salvadoreñas hay una considerable cantidad de restos de navíos; y quién sabe qué más esconde el mar en sus profundidades. La cuestión es que cada vez más se presentan amenazas en gran parte por los conocidos como "cazadores de tesoros"; pero también por gente en busca de chatarra que saquea, y con ello destruye estos bienes culturales. Además de la dispersión, ya que cuando los objetos son recuperados enfrentan el riesgo de destrucción debido a la falta de una conservación apropiada.

Los sitios arqueológicos en las profundidades del lago de Güija han sido presa de pillaje por robos de gran envergadura. La explotación comercial de sitios sumergidos y la consecuente venta de artefactos es una reminiscencia de lo que sucedió con innombrables sitios arqueológicos en tierra. La ineficacia de las legislaciones y el incompetente personal que ocupa los puestos políticos permiten a los cazadores de tesoros continuar sus actividades y explotar ar- 
tefactos con propósitos puramente mercantiles, con un total desprecio por la pérdida que ocasionan a la ciencia y la humanidad.

En este sentido, este número de la Revista Kóot, inicia con una contribución de la antropóloga y conservadora Melissa Campos, el artículo que titula "El potencial de los museos en la conservación del patrimonio cultural", que es el resultado de una reflexión que parte de la investigación titulada "Propuesta para un museo sin muros para la reactivación de la memoria urbana en la calle Arce", en la que formula una propuesta museológica de exposición en la vía pública para crear un vínculo real entre la comunidad y el patrimonio cultural del centro histórico de San Salvador, iniciada en 2011, a partir de los estudios en Maestría en Patrimonio Cultural y Territorio realizados en la Pontificia Universidad Javeriana de Colombia, tomando como caso de estudio el proceso de reordenamiento de la calle Arce en la ciudad capital de nuestro país. Se trata, sin más, de un aporte actualizado en la búsqueda de una propuesta para un museo abierto en todo este amplio panorama que nos ofrece la histórica calle Arce en el propio centro capitalino.

Por su parte, el arqueólogo Roberto Gallardo, de la Dirección de Arqueología de la Secretaría de Cultura de la Presidencia, presenta un amplio estudio de arqueología subacuática que titula "Registro y documentación histórica del pecio SS Colón en Acajutla, departamento de Sonsonate, El Salvador". De acuerdo con Gallardo, "aunque la navegación a larga distancia en el Pacífico centroamericano empieza con la presencia europea en el siglo XVI, la época de finales de 1800 y principios de 1900 es de especial importancia para nuestro país, ya que los vapores se convierten en parte del engranaje que impulsa las economías nacionales. Para finales del siglo XIX el libre mercado y la exportación de productos, especialmente el café y añil, hacen que el gobierno de El Salvador genere altos ingresos económicos. Estos cambios se reflejaron en la sociedad de la época, incluyendo la infraestructura, instituciones y en las estructuras sociales que se definieron marcadamente. Aunque este fenómeno de desarrollo y formación nacional es complejo y sus causas son múltiples, los vapores fueron parte del engranaje que formó El Salvador que conocemos actualmente. El tránsito de buques a vapor en el océano Pacífico entre 1850 y principios de 1900 fue un fenómeno histórico descomunal en América, y marca la época de oro en la navegación con máquinas impulsadas con este tipo de combustión. Durante este período se estableció un complejo sistema de transporte y comunicación que unió los continentes, y constantemente se rompieron marcas de tiempo en viajes marinos y capacidad de carga. 
Este fenómeno náutico fue vital para el desarrollo industrial y económico de muchos países en el continente americano. La gran cantidad de productos que eran transportados por estos buques, incluyendo añil y café, generaron los ingresos para hacer posible el desarrollo de los países que contaban con puertos en el océano Pacífico. El transporte de miles de pasajeros con diversas profesiones y especialidades, o simples aventureros que buscaban una mejor vida, también propició el traslado de conocimiento para el impulso tecnológico de muchas naciones americanas. El papel vital de los buques de vapor para la formación de El Salvador como nación y como país en desarrollo es un tema que amerita estudio para conocer sobre estas naves que fueron los medios de transporte y comunicación marítima más importantes durante gran parte del siglo XIX y principios del XX. Muchos buques a vapor que estuvieron en uso durante la segunda mitad del siglo XIX fueron desmantelados y otros desaparecieron en los mares, desconociéndose actualmente su paradero. Todos los vapores que naufragaron y que posteriormente fueron identificados se han convertido en verdaderos sitios arqueológicos y son parte de nuestro patrimonio cultural. Cada uno de estos pecios tiene su propia historia y su influencia en las sociedades, no solamente se limitó al desarrollo económico y social de El Salvador sino también de otros países latinoamericanos, europeos y de Estados Unidos. Estos pecios son los únicos sitios arqueológicos en El Salvador que han ejercido una influencia directa en la historia de otras naciones. Actualmente, el SS Colón es un sitio arqueológico subacuático ubicado en la playa de Acajutla, en el departamento de Sonsonate. Este es uno de los pecios mejor documentados históricamente y más importantes en El Salvador. Su relevancia sobrepasa las fronteras políticas pasadas y actuales, ya que este vapor estuvo presente en acontecimientos internacionales trascendentes, como el traslado de tropas estadounidenses hacia Filipinas durante la guerra entre Estados Unidos y España; el transporte de inmigrantes portorriqueños desde Los Ángeles a Hawai; levantamientos revolucionarios, tráfico de opio, así como fue testigo en la vida y muerte de personajes importantes. El SS Colón es un verdadero sitio arqueológico que debe ser protegido e investigado para las futuras generaciones. A continuación se presenta un informe sobre el registro y documentación histórica de este pecio". De hecho, es un estudio que, estamos seguros,se convertirá en un referente de primer orden en los estudios de arqueología subacuática en nuestro país.

El antropólogo guatemalteco Carlos René García Escobar, de la Escuela de Historia de la USAC, nos ofrece un interesante artículo que presentó como ponencia en el IX Congreso Centroamericano de Antropología que se realizó 
el presente año. "El plástico en el arte popular y el arte moderno contemporáneo en Guatemala" es el título del artículo, en el que afirma que "desde el pasado siglo XX, específicamente después de la II Guerra Mundial, Centro América, como muchos territorios nacionales del llamado tercer mundo, o también como parte de los denominados países subdesarrollados, ha sufrido con más intensidad que nunca la penetración desmedida y abusiva de los intereses económicos y políticos de las potencias autodenominadas 'superdesarrolladas', en términos de penetración de sus mercados de productos industrializados, en el contexto de sus modernas tecnologías, auxiliándose del usufructo de aranceles de exportación/importación favorables a las megaindustrias mono y polipólicas, en desmedro de las pobres y débiles economías de estos pueblos tercermundistas. Como fenómeno de inequívoca penetración de intereses capitalistas extranjeros, ha permeado durante los recientes lustros una paulatina intromisión de tipo comercial fundamentalmente, pero con la máscara de la innovación cultural que ha transformado los productos culturales nacionales, caracterizándolos con innovaciones de tipo industrial, por un lado (en el orden de las artesanías por ejemplo), y a su vez, por intercurso de los massmedia(medios de comunicación para las masas), las poblaciones pertenecientes a estas sociedades dependientes del capital internacional han adquirido hábitos nuevos tendientes a un cambio de conciencia identitaria que las conduce a olvidar o abandonar hábitos y comportamientos de corte tradicional como herencias ancestrales asumidas a través del pasado reciente y antiguo, en aras del consumo de productos y quehaceres nuevos que transforman estas identidades e inciden en gustos y hábitos que conducen a su vez en el deterioro físico de los organismos vivientes y las personas. En otro sentido, el plástico se ha introducido como elemento coadyuvador para otorgar sentido estético y simbólico en expresiones materiales con pretensiones artísticas y de mensaje social o sociológico, como veremos aquí más adelante". Se trata de un artículo que, sin lugar a dudas, no vale solo para Guatemala sino que a su vez nos da elementos de juicio para repensar lo que sucede en nuestro país con ese producto popularizado y conocido como plástico.

El antropólogo Miguel Lisbona Guillén del Proimmse-IIA, Universidad Autónoma de México, contribuye con un interesante artículo titulado "Un carnaval inventado: el disfraz de lo zoque en el Chiapas contemporáneo". Se trata de un aporte que tiene comofinalidad el reflexionar sobre una fiesta nacida en el año 2007: el Carnaval de Copoya, una localidad perteneciente al municipio de Tuxtla Gutiérrez, capital del estado de Chiapas, México. La carnes- 
tolenda no es una construcción reciente en el mundo, y tiempo habrá en estas páginas para profundizar en ello; pero sí llama la atención que en la localidad de Copoya, a escasos cinco kilómetros de la capital chiapaneca, surgiera una festividad cuando ya existía un carnaval celebrado conjuntamente por los que se reconocen como zoques en Copoya y en Tuxtla Gutiérrez. Miguel Lisbona parte de que, "por historiadores y antropólogos es conocido el pasado zoque del centro de Chiapas, y en concreto de su capital y de Copoya, lugar fundado en el siglo XIX por hablantes del idioma zoque, como ha descrito con precisión Dolores Aramoni. Hablantes de tal idioma todavía viven en los estados de Chiapas, Oaxaca, Tabasco y Veracruz, alejados de los grandes centros urbanos del país, cuya cercanía ha influido para que muchos lugares donde históricamente se habló el zoque hayan perdido de manera paulatina hablantes, como ha ocurrido en Copoya, donde ya casi no se hallan. La existencia de este idioma, del tronco lingüístico mixe-zoque-popoluca, tampoco es una exigencia identitaria, como rasgo cultural inamovible, para que los copoyeros o ciertos habitantes de Tuxtla Gutiérrez se asuman como zoques o, al menos, como descendientes de ellos. Tampoco es de extrañar que lo zoque se encuentre presente en la capital en forma de apellidos, sabores alimenticios y en una serie de festividades que conforman un complejo entramado de cargos relacionados con devociones católicas, casi todas ellas uniendo a habitantes de Tuxtla Gutiérrez y Copoya, como han apuntado algunos estudios; y también lo sigue haciendo de manera incansable la ya mencionada antropóloga Aramoni. El carnaval conjunto de Tuxtla Gutiérrez y Copoya es un ejemplo de dicha colaboración, aunque en la actualidad han aparecido versiones distintas de tal festividad en la capital chiapaneca y en Copoya. Pero si la presencia de lo zoque está viva en el estado de Chiapas, tanto en los municipios donde prácticamente toda la población es hablante del idioma, y también de diversas formas en la capital chiapaneca y en la misma localidad de Copoya, ¿qué sentido tiene la invención de un carnaval cuando ya existía uno? De esta pregunta surgió la idea de escribir este texto, interrogante consciente de las suspicacias que puede conllevar, aunque no exenta de interés por seguir pensando las múltiples formas en que se nombre y utiliza lo zoque". Artículos como estos nos deben llevar a reflexionar sobre esos inventos culturales que se presentan a menudo y que a la larga no son más que copias de expresiones culturales ya existentes en otros contextos o simplemente ocurrencias sin arraigo étnico. El hecho es que, cuando estos subterfugios culturales se presentan, si no tienen un referente identitario, muy pronto se van al "baúl de los olvidos", por no decir desaparecen. 
Por su parte, el antropólogo William R. Fowler, de la Vanderbilt University, y la estudiante egresada de Antropología de la Universidad de El Salvador Eugenia Zavaleta Lemus, de la Universidad de El Salvador, dan su aporte a este número con un artículo teórico-reflexivo, tomando como base a Pierre Bourdieu, con el tema"El pensamiento de Pierre Bourdieu: apuntes para una mirada arqueológica". Fowler y Zavaleta abordan a uno de los teóricos contemporáneos de la acción social más estudiados en diferentes campos de las ciencias sociales; y como ellos muy bien lo manifiestan, "sus postulados invitan a la superación de las antinomias o los dualismos clásicos de la sociología tradicional (objetivismo/subjetivismo, estructura/agencia, individuo/sociedad, materia/idea, micro/macro, cuali/cuanti), y porque se ha identificado con la superación de los determinismos y sustancialismos, construyendo enfoques más relacionales y procesuales. Sus principales influencias teóricas provienen del marxismo, del estructuralismo francés, de las filosofías de Martin Heidegger, Edmund Husserl, Maurice Merleau-Ponty, Raymond Aron y Ludwig Wittgenstein; inclusive, de la tradición epistemológica francesa que enfatiza el no-positivismo y antievolucionismo. Es, junto a Anthony Giddens, calificado como uno de los dos teóricos de la práctica más influyentes del siglo $\mathrm{XX}$, que Bourdieu ha producido una "ontología de las prácticas sociales que busca superar a nivel metodológico y analítico los dualismos de la física y la fenomenología social" y que constituye una "síntesis superadora" de los debates sustancialistas y que abona igualmente al análisis teórico como al empírico. Esta ontología descansa en categorías sociológicas potentes como habitus, campo, dualidad de la estructura e integración social y sistémica. Para Bourdieu, la sociedad existe bajo dos formas: los campos (instituciones), que conforman las estructuras sociales externas, y los habitus (disposiciones), que constituyen la organización interna de los agentes. Bajo la tradición del pensamiento relacional, Bourdieu concibe a la sociedad a partir de la comprensión de su carácter heterogéneo y enfatiza en la necesidad de abordarla como un sistema de campos diferenciales cuyos espacios de lucha diversos son relativamente independientes y autónomos, en contraste con las teorías sociales en que la sociedad es un todo homogéneo, integrado y armónico. Estos campos de lucha son los escenarios en que se mueven los agentes sociales y desde los cuales establecen relaciones que pueden variar desde la dominación hasta la resistencia.

Fowler y Zavaleta, en su artículo, y como ellos mismos muy bien lo concretizan, muestran "algunos de los principales debates de la teoría sociológica y la teoría social que enmarcan el contexto del pensamiento de Bourdieu, como de 
sus categorías de análisis. Después, presentaremos las categorías y conceptos bourdieusianos que pueden explicar los procesos de diferenciación y transformación social con el objetivo de señalar su utilidad en la teoría arqueológica".

En buen ahora. Por su parte, el presbítero Roque Marcelino Regalado, en su interesante artículo, afirma que "en la mayoría de religiones el hombre siempre ha expresado las realidades trascendentes con una visión antropomórfica. En especial en el judaísmo como en el cristianismo, esta visión ha llevado a atribuir características a Dios que han inspirado la representación plástica del mismo. Así, cuando se describe en los textos sagrados que Dios oye, ve, camina con su pueblo, abraza, golpea, tiene una espada en su mano, etc., se trata de expresiones de la cercanía de la trascendencia de Dios. Esta expresión plástica, con el paso del tiempo, en el cristianismo tomó forma en las artes occidentales, de tal manera que la cultura plástica de los pueblos se vio revestida de sacralidad. Sin embargo, con la llegada de la cultura moderna, con su producción en masa y la visión de lo desechable, nos ha hecho perder el valor de lo sagrado y de lo cultural. Es necesario recobrar el espíritu de la humanidad y los valores que de la cultura y la fe emanan". El artículo del presbítero Regalado se titula "Los bienes temporales de la iglesia: tesoros sagrados para la comunidad cristiana y tesoros culturales para los pueblos".

El honorable embajador de la República de Cuba acreditado en nuestro país, Dr. CS. Pedro P. Prada, en ocasión del 160 aniversario del natalicio del gran pensador de todos los tiempos José Martí, ofreció una interesante conferencia el 28 de enero del presente año a la comunidad académica y estudiantil de esta casa de estudios, y, por su relevancia, Kóot publica integra esta interesante reflexión que él tituló "José Martí en la hora de la integración latinoamericana y caribeña".

Esta revista, que es posible gracias a los colabores arriba mencionados y al equipo de editorial, es un aporte muy interesante en la ciencia y la cultura, y nos hace reflexionar; pero principalmente nos motiva a seguir investigando para descubrir, y con ello poner en valor, tan importantes referentes culturales.

Dr. Ramón D. Rivas

Director. Dirección de Cultura

Editor. Revista de Museología Kóot

Universidad Tecnológica de El Salvador 


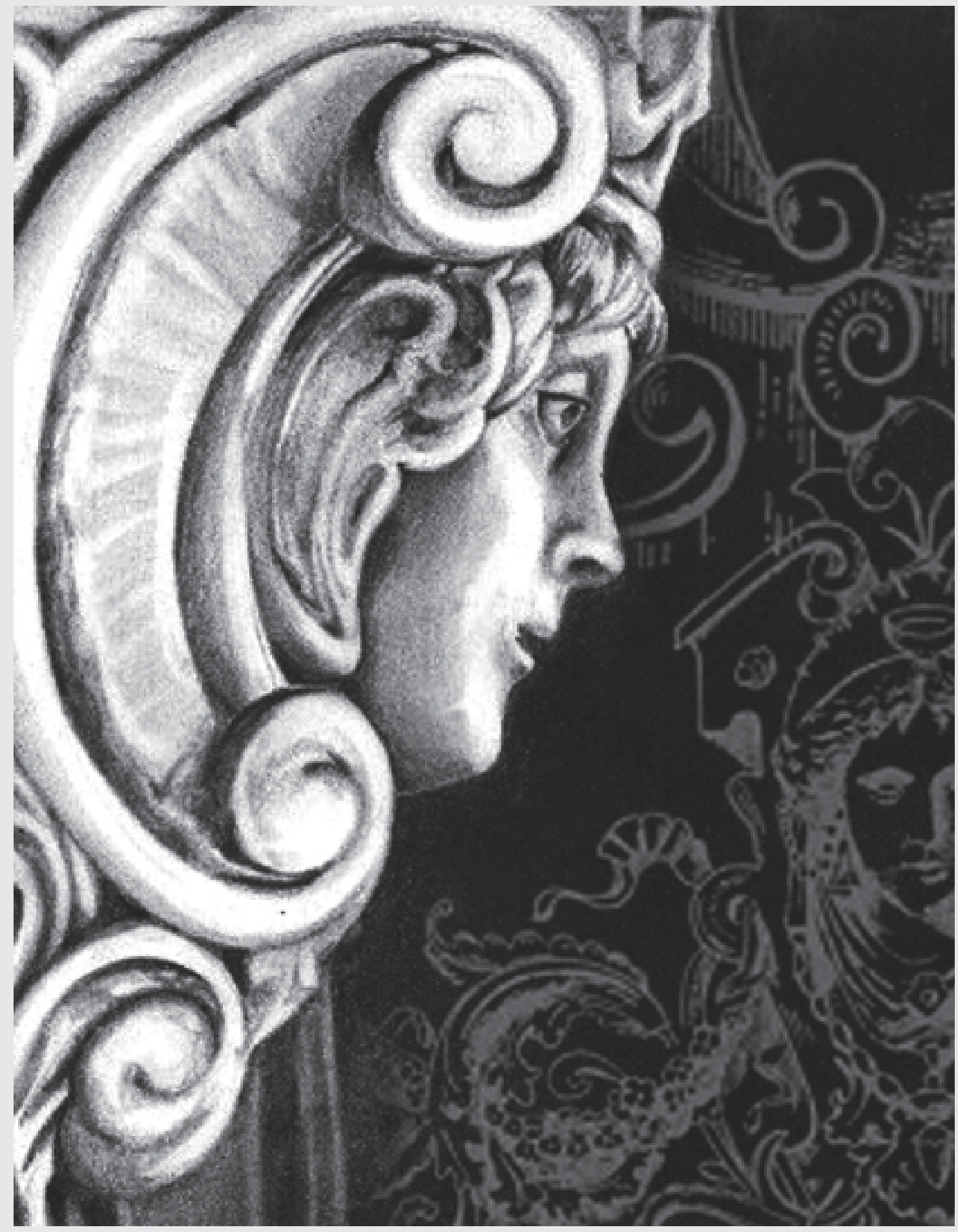

Musa. Detalle arquitectonico de la fachada del Museo Universitario de Antropología, MUA. Técnica mixta, 8.5” x 11”, Rita Araujo. 2012. 